\title{
Cruzando el Rubicón: Se podrá estudiar Medicina en un Centro Universitario de la Defensa
}

La Sanidad Militar (SM) ha sufrido profundos cambios en la última década, en la que ha pasado de ser una Sanidad eminentemente asistencial, que tenía a su cargo la atención sanitaria a todo el personal militar y sus familias, a una Sanidad con una predominante naturaleza logístico operativa, que ha de dar respuesta a un apoyo sanitario a las FAS, no solo en territorio nacional sino también en las misiones internacionales en las que participan nuestras Fuerzas Armadas y en estos casos con la exigencia de unas condiciones de calidad que han de ser similares a las que disfrutan en territorio nacional.

Debido a estos condicionantes, se han llevado cabo modificaciones sustanciales en la estructura de la SM, fundamentalmente la unificación de Sanidades de los Ejércitos y la Armada, así como la disminución sustancial de Hospitales y Clínicas Militares.

Ambos procesos, el cambio de la misión fundamental, asistencial por la logístico-operativa, y la reordenación de las estructuras sanitarias, han obligado al desplazamiento de personal y han repercutido de forma decisiva en los recursos humanos, sobre todo en los médicos.

Si a ello se añade que en la sanidad civil, durante los últimos años, ha existido una gran demanda de especialistas bien formados, en condiciones muy ventajosas frente a la Sanidad Militar, el resultado ha sido una pérdida elevada de efectivos, no compensada con el número de ingresos.

En una década hemos pasado de más de 1500 a menos de 800 médicos militares, con un nivel de aspirantes a ingreso en SM que era de 6 por plaza convocada en el 2002 y de 0 en el 2007. Desde el 2004 hasta el 2012 no se han cubierto las plazas ofertadas. En los próximos 6 años pasarán a la reserva por edad en torno a 400 médicos.

Como se ve la situación es muy preocupante y requiere acciones contundentes y decisivas encaminadas a paliar la sangría que supone el pase a la situación de reserva de efectivos, especialmente la de los médicos que abandonan la Sanidad Militar de forma voluntaria (excedencias) en plena madurez profesional y cuando es máximo su rendimiento efectivo.

Pero ello debe ser acompañado por un nuevo sistema de captación adaptado a la situación actual y a los requerimientos de apoyo sanitario de calidad a los Ejércitos.

Para lo primero se trata de hacer una Sanidad Militar atractiva, competitiva con el entorno, de calidad y prestigio y para lo segundo se trata de desarrollar un sistema que aúne la captación, la formación y un futuro de profesional de carrera, cuyo modelo recientemente aprobado es el objeto de esta Editorial.

Los requerimientos en los que se ha basado el modelo han sido, por una parte ofrecer la posibilidad de ingresar en el Cuerpo Militar de Sanidad (CMS) a un número de aspirantes suficientes para que pueda hacerse una selección adecuada y por otra realizar una formación tanto sanitaria como militar adaptada al contexto actual de actuación de la SM.
Así se decidió que los aspirantes fueran acogidos sin titulación previa, cumplidos los requerimientos generales de ingreso a los estudios universitarios.

Además, para conseguir los objetivos, era necesario establecer unos mecanismos de compromiso de permanencia en las FAS por parte de los ingresados y contar con un sistema docente que permitiera a la vez desarrollar los programas de Graduado en Medicina como en cualquier Facultad de nuestro país y una formación militar específica y técnica.

Para ello contábamos con la experiencia en la formación de graduados médicos en el Hospital Central de la Defensa "Gomez Ulla", el Convenio vigente con la Universidad de Alcalá de Henares y la experiencia docente de la Escuela Militar de Sanidad (EMISAN).

Por tanto era necesario, establecer un sistema de ingreso justo, que fuera aceptado por la Sociedad, establecer un compromiso de permanencia no solo durante el tiempo que duran los estudios, sino también una vez concluidos y por último un sistema docente que hiciera compatible la formación sanitaria con la militar.

De acuerdo con la IGESAN, DIGEREM y el Ministerio de Educación, se decidió que el único modelo capaz de conseguir los tres objetivos era el modelo de Centros Universitarios de la Defensa, (CUD), existente para la formación de oficiales de los tres ejércitos, adaptado a las especiales características de los estudios de graduado en Medicina.

Con todo ello ha sido necesario realizar una serie compleja de actuaciones que han tenido como resultado la creación del Centro Universitario de la Defensa ubicado en el Grupo de Escuelas de la Defensa de Madrid (Orden DEF/734/2012 de 11 de abril).

Previamente, para posibilitar el ingreso de aspirantes sin titulación al CMS, se ha tenido que modificar la disposición adicio-

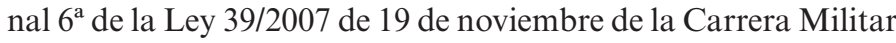
mediante la Ley Orgánica 9/2011 de 27 de julio, publicar una orden ministerial (DEF/689/2012 de 30 de marzo) que aprueba las normas por las que han de regirse los sistemas de selección y la firma de un Convenio especifico con la UAH, como lo determina el RD 1723/2008 de 24 de octubre, de creación de Centros Universitarios de la Defensa.

Está pendiente, en estos momentos la modificación del RD de ingreso 35/2010 de 15 de enero, en el que entre otras cosas se especifican los límites de edad para ingresar sin titulación en el CUD y la posibilidad de ingresar con estudios de Medicina ya comenzados en otras Universidades.

De forma esquemática, el ingreso en el CUD para realizar los estudios de Graduado en Medicina se puede realizar

1. Por acceso directo, desde el bachiller, con las mismas condiciones que para el ingreso en cualquier facultad de medicina (RD 2008 1892/2008 de 14 de noviembre), además 


\section{Editorial}

de las pruebas de inglés, físicas, psicológicas y reconocimiento médico.

2. También se puede ingresar por promoción por cambio de Escala o por cambio de Cuerpo: en el primer caso solo pueden realizarlo los Oficiales enfermeros, se les exige un concurso de meritos, y a los segundos además del concurso de méritos una prueba selectiva de biología y química.

Una vez ingresados se incorporan a la EMISAN como cadetes, realizando los estudios de Medicina de los primeros cursos junto a la Formación Militar general.

Concluidos estos estudios se les promoverá a alféreces alumnos, continuando sus estudios de medicina y los militares específicos y técnicos hasta finalizar el grado, momento en el que adquieren el Empleo de Teniente Médico, pasando a ser militares de carrera.

A partir de ese momento el compromiso de permanencia en el CMS es de 12 años. Se determinará en qué momento comienzan la especialidad complementaria, en cualquier caso será muy pronto una vez concluidos los estudios de grado, de la misma forma que se determinará un nuevo compromiso de permanencia si lo hubiere.
Finalizados los años de permanencia, el Oficial Médico podrá optar por continuar en la SM o bien rescindir el compromiso.

Sin duda que lo antes expuesto supone un salto cualitativo y la cristalización de la aspiración de no pocos médicos militares, amén del hallazgo de una nueva vía de captación con la garantía pragmática de su éxito frente a similares problemas en Naciones Aliadas y de modo muy singular tanto en la República Francesa como en la República Federal Alemana.

Como titulo la Editorial, es un momento histórico que puede compararse, salvando las distancias, con el paso del río Rubicón, que marcaba la frontera entre su País y la Galia Cisalpina, por las tropas al Mando de Julio César.

Sin duda, un paso decisivo afrontando un riesgo, a la espera de unos beneficios que se derivarán de la explotación del éxito que todos esperamos.

Debo finalizar con mi gratitud a cuantos hacen posible esta feliz realidad.

Juan Manuel Montero Vázquez Inspector General de Sanidad de la Defensa de España

Por Resolución 452/38040/2012, de 25 de mayo, de la Subsecretaría del Ministerio de Defensa (BOE n. ${ }^{129}$, de 30 de mayo de 2012), se ha convocado el primer proceso de selección de ingreso para la incorporación como militar de carrera a la Escala de Oficiales del Cuerpo Militar de Sanidad, especialidad fundamental Medicina, por este novedoso procecimiento. 